\title{
CONSTITUCIÓN EN CHILE Y SOCIEDAD MUNDIAL*
}

\author{
Carolina Busco**
}

\begin{tabular}{l|l}
\hline RECEBIDO EM: & 23.12.2020 \\
\hline APROVADO EM: & 19.2 .2021 \\
\hline
\end{tabular}

* Este trabajo ha sido financiado por el Proyecto Fondecyt 1140106.

** Socióloga por Pontificia Universidad Católica de Chile y PhD en Ciencias Políticas y Sociales por la Università degli Studi di Macerata. Actualmente es académica de la Facultad de Ingeniería y Ciencias de la Universidad Diego Portales en Chile. Sus líneas de investigación son: Digitalización de la sociedad y las organizaciones; Gestión de teletrabajo; Gestión de stakeholders y Transporte y sociedad. E-mail: cbusco@cbestudios.cl 
- CAROLINA BUSCO

- RESUMEN: Este artículo levanta diferentes demandas por cambios constitucionales en Chile y analiza el rol de la Constitución en el contexto de la sociedad mundial, relativizando su definición en tanto ley suprema. Basado en conceptos de sociología jurídica y los planteamientos de Niklas Luhmann, analiza diferentes casos a partir de los cuales concluye que una de las consecuencia de lo observado es que al desligar el tipo de derecho de la estructura organizacional que lo produce, la descripción del derecho como algo nacional o transnacional deja de ser relevante y el actor se encuentra entonces ante la posibilidad de elegir entre grupos de leyes. Entre estos grupos está la constitución, a la cual se puede o no apelar para enfrentar un conflicto frente a un incumplimiento de expectativas. Se demuestra así la contingencia de la constitución respecto de otras fuentes jurídicas y levanta el problema de la híper-complejidad normativa.

\section{CONSTITUIÇÃO NO CHILE E SOCIEDADE MUNDIAL}

REsUMo: Este artigo levanta diferentes demandas por mudanças constitucionais no Chile e analisa o rol da Constituição no contexto da sociedade mundial, relativizando sua definição enquanto lei suprema. A partir dos conceitos de sociologia jurídica e das abordagens de Niklas Luhmann, analisa diferentes casos em que se conclui que uma das consequências do que se observa é que, ao separar o tipo de direito da estrutura organizacional que o produz, a descrição do direito como algo nacional ou transnacional deixa de ser relevante e o ator fica, então, diante da possibilidade de escolher entre grupos de leis. Entre estes grupos está a constituição, à qual se pode ou não recorrer para enfrentar um conflito frente a uma quebra de expectativas. Assim, demonstra-se a contingência da constituição em relação a outras fontes legais, e levanta-se o problema da hipercomplexidade normativa.

\section{CONSTITUTION IN CHILE AND WORLD SOCIETY}

- abstract: This article identifies different social demands for constitutional change in Chile and analyzes the role of the Constitution in the context of world 
society, relativizing its definition as supreme law. Based on concepts of legal sociology and the work of Niklas Luhmann, this work analyzes different cases, concluding that by separating the type of law from the organizational structure that produces it, the description of individual rights as something national or transnational ceases to be relevant and the actor is then faced with the possibility of choosing between groups of laws. Among these groups is the constitution, to which one may or may not appeal to confront a conflict in the presence of an infringement of expectations. The contingency of the constitution with respect to other legal sources is thus demonstrated and raises the problem of normative hyper-complexity.

\section{Introducción}

Chile actualmente pasa por un momento especial. Se escucha en diferentes ámbitos la necesidad de cambiar su actual constitución, entendiendo que, como ley positiva, debe adaptarse a los cambios sociales experimentados en nuestro país. Los partidos políticos no han sido capaces de articular adecuadamente las demandas ciudadanas y eso los ha llevado a perder convocatoria. Hay una baja participación en procesos electorales que no parece coherente con la efervescencia de los movimientos estudiantiles, las protestas referidas a los servicios de salud y las propias de las regiones. Pero movimientos de protesta similares también han ocurrido en otras partes del planeta (Hessel 2011), muchos de los cuales se oponen a los efectos de la globalización.

El objetivo general de la presente investigación es profundizar en los cambios en el sistema legal a la luz de la diferenciación funcional que acompaña al despliegue de la sociedad mundial. Con la especialización y creciente complejidad de los sistemas funcionales, el ordenamiento legal, sustentado en constituciones que se definen en relación a un territorio soberano, ha ido cediendo ante la internacionalización de regulaciones que profundizan la diferenciación sectorial.

Este trabajo observa el alcance que tiene la constitución en el Chile de hoy enmarcando su aproximación en la teoría de sistemas sociales, así como en la teoría de la evolución, cuya base se sustenta en los planteamientos propuestos por Niklas Luhmann.

El principal foco de la demanda por cambio constitucional en Chile, dice relación con la ilegitimidad de la actual constitución, debido a su origen en tiempos de dictadura. 
La constitución actual ha sido reformada en 52 oportunidades, siendo la última el 27 de agosto de 2020. Por otra parte, durante el segundo período presidencial de Michelle Bachelet (2014-2018) se desarrollaron una serie de iniciativas tendientes a generar una proceso ciudadano participativo con el fin de elaborar una nueva constitución. Sin embargo, desde la sociedad no se observaba un "momento constitucional" en los términos de Ackerman (1999), donde la comunidad piense activamente y delibere sobre las bases fundantes de la sociedad que desea. Se trataba más bien de demandas parciales, planteadas por grupos organizados, respecto de asuntos que se asocian a los diferentes subsistemas.

Con el estallido social ocurrido el 18 de octubre de 2019 y el posterior acuerdo por la paz establecido el 15 de noviembre de ese mismo año, surge probablemente un verdadero momento constitucional, trayendo como consecuencia el reciente plebiscito (25 de octubre de 2020). En esta última instancia se aprobó con un 78,27\% la elaboración de una nueva constitución, la que será redactad por una convención constituyente (opción que recibió el 78,99\% de los votos). Si bien el origen autoritario de la constitución de 1980 es uno de los argumentos que con mayor frecuencia se esgrimen a favor de una nueva carta magna, con este análisis se busca demostrar que la necesidad de adaptar esta ley fundamental responde a los cambios propios de una sociedad más compleja y plenamente inmersa en la sociedad mundial.

Brevemente, la constitución chilena de 1980 es una estructura normativa de la cual se desprenden Leyes Orgánicas Constitucionales: apartados legales específicos considerados de carácter constitucional. El planteamiento que surge de esta investigación es que las demandas por cambios constitucionales realizadas previas al estallido social se asociaban a demandas desde los sistemas funcionales, respecto de aspectos más bien "funcionales" de la constitución. Por ejemplo: Los estudiantes se agruparon para reclamar por la Ley Orgánica Constitucional de Enseñanza; los habitantes de las diferentes regiones del país se organizaron para criticar el excesivo centralismo de la estructura estatal chilena, orientando sus demandas a la "Ley Orgánica Constitucional de la Administración Pública”. Desde el ámbito de la política, la demanda ha venido desarrollándose en torno al sistema binominal, orientando sus críticas a la Ley Orgánica Constitucional sobre Votaciones Populares y Escrutinios, (esta última fue finalmente modificada en 2015). 


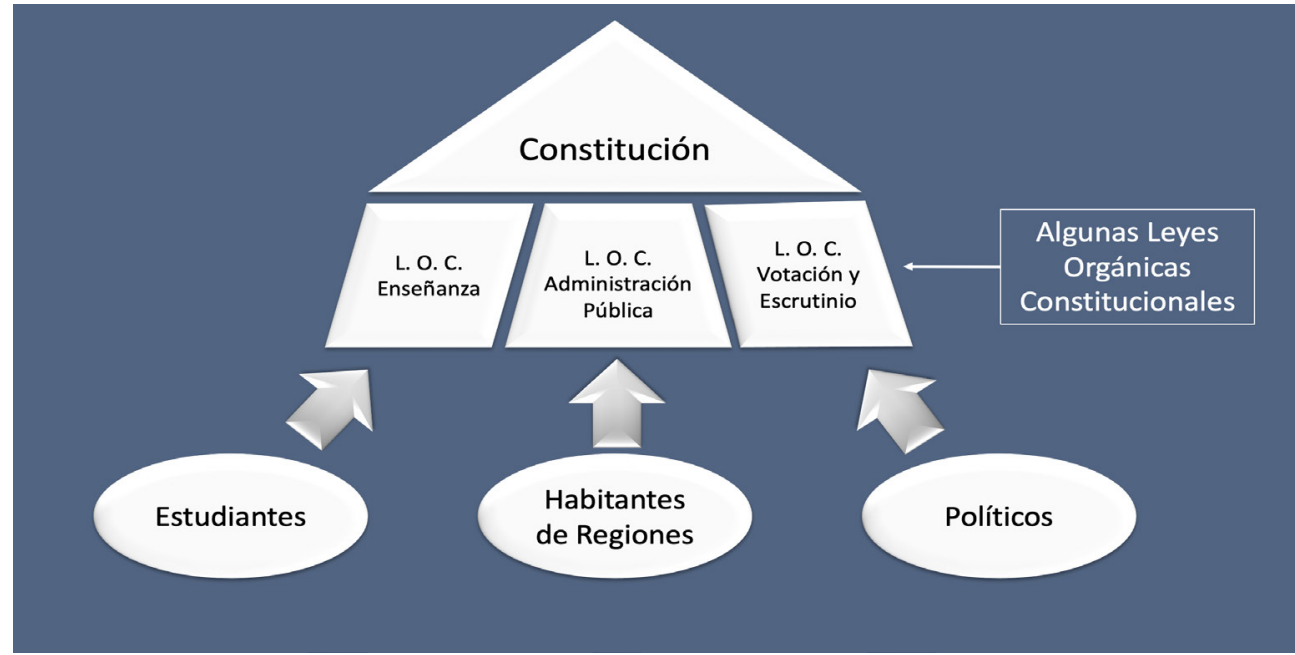

FUENTE: ELABORACIÓN PROPIA.

Probablemente la Constitución es el objeto más apropiado al cual dirigir todas estas demandas, y cuando se critica tanto la educación como el excesivo centralismo en Chile, es menester observar y discutir una nueva manera de redefinir las expectativas normativas. Sin embargo, en el contexto de creciente complejización de la sociedad mundial, se abren otras alternativas en la cuales muchas de las demandas sociales pueden tener una resonancia incluso mayor que la que se tiene apelando a la constitución nacional, lo que lleva a reflexionar además sobre el alcance y flexibilidad estructural de una nueva constitución.

Con el fin de cumplir con los objetivos aquí propuestos, este trabajo parte de la pregunta por el rol de la constitución en Chile, para lo cual es necesario resumir brevemente algunos de los cambios a los cuales se ha visto enfrentado el país en su inmersión en la sociedad mundial, lo que probablemente se ve fuertemente incidido por el proceso de apertura y desarrollo económico. Esto provoca una serie de transformaciones que en poco tiempo terminan configurando una sociedad muy distinta a la que tradicionalmente caracterizó a Chile. El sociólogo Eugenio Tironi escribe en su libro denominado "El cambio está aqui’ la siguiente frase para describir los albores del siglo XXI: "El Chile de hoy no es el mismo en lo económico, político y social. Se impone gobernar el cambio ahora, en medio de la incertidumbre, la competencia y el temor" (Tironi 2002). Se trata de una sociedad nueva que enfrenta una secuencia de cambios cada vez más intensos, 
lo que desemboca en un sustancial incremento de la complejidad. El aumento de las posibilidades de elegir, en todo ámbito, provoca el temor propio de no tener un patrón de selección claro, pues las estructuras tradicionales que contuvieron lo social hasta hacía poco, ya no parecen apropiadas.

Este proceso implica cambios profundos en los estilos de vida, no sólo por la apertura económica, sino porque se impone como un modelo de desarrollo importado. El neoliberalismo no sería entonces un producto propio de nuestra sociedad - como sí lo es en Inglaterra, Holanda o en los Estados Unidos -, sino una revolución desde arriba paradójicamente anti-estatal, en una nación formada por el Estado (Góngora, 2006).

El rol del estado en cambio ha permanecido relativamente estable. Uno de los defensores de la tesis del desarrollo de Chile guiado por el estado es Mario Góngora, proponiendo que este antecede en Chile a la formación de la nación y la cultura, constituyéndose en su principal configurador. Lo anterior se ve respaldado por la siguiente cita:

Por muy democrático que se haya considerado a Chile a lo largo del siglo XX, no siempre, pero a menudo, es un hecho que el país se ha dejado dirigir por el Estado. Los gobiernos locales han sido francamente inexistentes, las redes asociativas han dependido fuertemente del apoyo del estado administrativo, y siempre han sido absorbidas por la política nacional. Los medios de comunicación se han sometido a una estricta supervisión, cuando no han sido abiertamente supervisados por los gobiernos de turno. Hasta hoy, incluso, en la educación fiscal y su supervisión pública han marcado los estándares culturales del país (Jocelyn-Holt 1992: 53).

Sin embargo, el historiador Jocelyn-Holt atribuye más importancia a la elite en ese proceso de dirigir el país, lo que no dista mucho de la interpretación de Góngora, ya que es precisamente la elite la que se hace cargo del Estado en términos políticos - la clase media educada participa en el estado solo como tecnócratas - y desde ahí desarrolla un gobierno tradicional y aristocrático:

Lo que suele aparecer como estado, por tanto, no es más que un poder oligárquico que tiende a confundirse con una estructura supuestamente impersonal. El estado como tal no era otra cosa que el instrumento de una elite social cuya base de poder residió en la estructura social más que en el aparato propiamente estatal, siendo este último sólo un instrumento auxiliar de la oligarquía (Jocelyn-Holt 1992: 27-28). 
Se ha tratado entonces históricamente de un Estado dirigista y aristocrático, y de una sociedad que además ha valorado de manera importante la figura del Presidente de la República:

Más de alguien ha señalado respecto de Ibáñez el 52 (y de Alessandri en 1958 y 1970) que el carisma de ambos se debía a que eran vistos como figuras paternales. Otro tanto se ha dicho recientemente sobre Aylwin y Pinochet. No hay que ser freudiano, en todo caso, para saber que en toda imagen paterna suelen entremezclarse, indisolublemente, respeto y temor (Jocelyn-Holt 1992: 198).

La presidencia de la república es considerada una institución importante, jugando un rol fundamental en el imaginario colectivo. Quién asume el poder ejecutivo es visto por la sociedad como representante del Estado y padre, siendo quien recibe las demandas populares. Esto explica por qué, aun hasta el día de hoy, la ciudadanía comprende al estado como depositario de sus demandas colectivas.

Por esta razón, el carácter central que posee el Estado en su rol modernizador y receptor de las demandas cada vez más diversificadas de la población es hoy un tema que se presenta especialmente crítico. Si a esto se suma que las canalizaciones de las demandas ya no necesariamente se hacen por medio de los partidos políticos - que producto del sistema binominal ${ }^{1}$ no supieron diversificarse y adaptarse a los requerimientos de una sociedad que había cambiado - la capacidad de reacción del estado frente a estas demandas se pone hoy en tela de juicio. Se trata de una sociedad que se vincula en red, se organiza por temas específicos y sus demandas están respaldados por las nuevas corrientes de defensa de los derechos individuales. Esta sociedad, más compleja y empoderada que nunca, solicita sus demandas a un estado que sigue funcionando como antaño, estructurado burocráticamente y con la lentitud operativa que se desprende de esa estructura organizacional.

1 Sistema Binominal corresponde al sistema electoral mediante el cual se eligen dos cargos por circunscripción o distrito, promoviendo una distribución equitativa entre dos fuerzas políticas mediante un resultado eleccionario que no necesariamente responde a la mayoría de votos. Fue establecido en Chile, para las elecciones parlamentarias -senadores y diputados (ley 18.799, de 26 de mayo de 1989), modificando la Ley Orgánica Constitucional sobre votaciones populares y escrutinios - ambas promulgadas durante el Régimen Militar. Actualmente está en trámite una reforma promovida por el gobierno de Michelle Bachelet que reemplaza el sistema binominal por uno proporcional. Esta fue aprobada por la Cámara de Diputados y continúa su trámite en el senado, entendiendo que es una manera de fortalecer la democracia. 
En este contexto, la violencia social, como una forma de expresión llevada a cabo por grupos pequeños y excluidos, comienza a gestarse años atrás como un nuevo problema social que presenta una de sus máximas expresiones el 18 de octubre de 2019. La diferenciación social no solo aumenta la complejidad, también amplía las expectativas posibles. Hoy en día, frente a tal diversidad social, es difícil estandarizar esas expectativas, mientras que el acto de demandar socialmente está siendo cada vez más legitimado.

Esta es sólo una breve descripción de la sociedad chilena - que deja fuera una serie de otros elementos tan relevantes como los ya mencionados -, pero sin embargo permite describir de manera adecuada el contexto en el cual se realiza este trabajo.

\section{Desarrollo}

Luhmann define la constitución, principalmente desde dos perspectivas. Como instrumento que facilita el acoplamiento estructural entre el sistema legal y el político, y como ley positiva. En esta ocasión concentraremos el análisis en el concepto de ley positiva, porque se asocia fácilmente a las nociones de contingencia, selección, cambio, evolución y complejidad.

En términos generales, entendemos que a mayor complejidad existe una mayor cantidad de posibilidades posibles, es decir, un aumento de las posibilidades a partir de las cuales podemos elegir. La posibilidad de elegir es lo que denominamos contingencia, es decir, cuando algo no es necesario ni imposible, sino que puede ser también de un modo distinto. El aumento de la contingencia es entonces expresión de complejidad, pues la evolución ha permitido el surgimiento de una serie de alternativas frente a las cuales podemos - y debemos - seleccionar. Este aumento de la complejidad, y en consecuencia de la contingencia, tiene también expresión en la constitución, cambiando así el rol que a esta le cabe en la sociedad como ley suprema.

"La positivización de la ley considera dos tipos diferentes de contingencias: la ley no solo es creada mediante una decisión, sino que también es válida mediante una decisión" (Luhmann 1985:161). El aumento de la complejidad, permitió a Luhmann distinguir en este proceso de positivización de la ley dos ópticas, una temporal, que establece que la ley puede variar a lo largo del tiempo y una material, ya que en la sociedad siempre están surgiendo nuevos comportamientos que deben ser normados. Asuntos como la propiedad intelectual de los alimentos transgénicos, la clonación, el matrimonio entre personas del mismo sexo y la posibilidad que estas parejas tienen de adoptar hijos, 
entre otros muchos nuevos asuntos sobre los cuales es necesario legislar, son efectivamente casos que han ido incrementando la complejidad del sistema legal, a través del aumento de los temas respecto de los cuales se decide o no redactar una nueva ley.

Siempre enfocados en la relación de la constitución con el sistema del derecho, en esta ocasión se busca levantar la posibilidad de observar la constitución como contingente desde otro punto de vista: desde la perspectiva del implicado, para quien no necesariamente constituye ley suprema.

Para comprobar aquello, se observa el rol de la constitución chilena desde la tensión entre lo global y lo local, en tanto es un instrumento que funda el orden estatal, pero que sin embargo co-existe con una serie de leyes que traspasan las fronteras nacionales. Para esto centraremos el análisis en Chile, pero no directamente en su constitución, sino más bien en el rol que ésta juega en dos ámbitos en los cuales se experimenta esta tensión: La cuestión Mapuche y El Tribunal Constitucional.

FIGURA 2

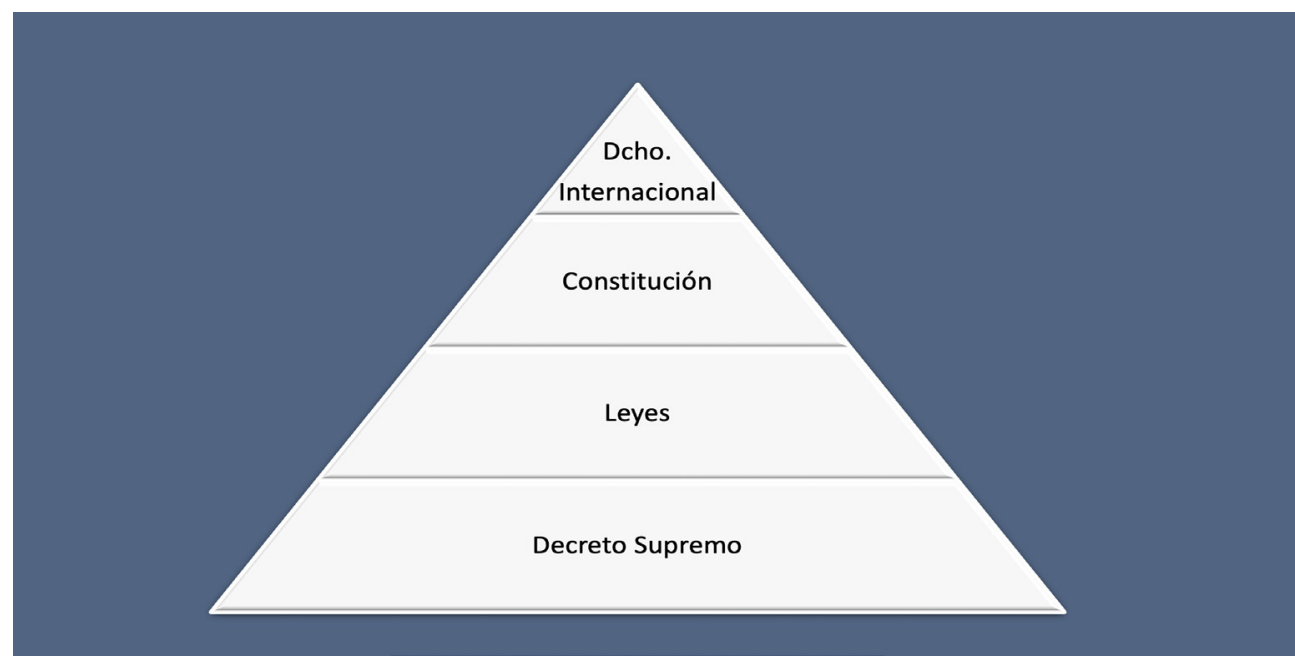

FUENTE: ELABORACIÓN PROPIA.

En otras palabras, se propone observar la constitución desde la perspectiva de quien se enfrenta a una serie de normativas frente a las cuales tiene la posibilidad de elegir. No se niega la existencia de la estructura jerárquica de la ley (Figura 2) - porque es un modelo que aun sirve para explicar muchas operaciones, especialmente en 
- carolina busco

el nivel nacional -, sino que se plantea que ese modelo convive con este otro esquema (Figura 3), lo que se puede demostrar a través del estudio de los casos que se presentan a continuación.

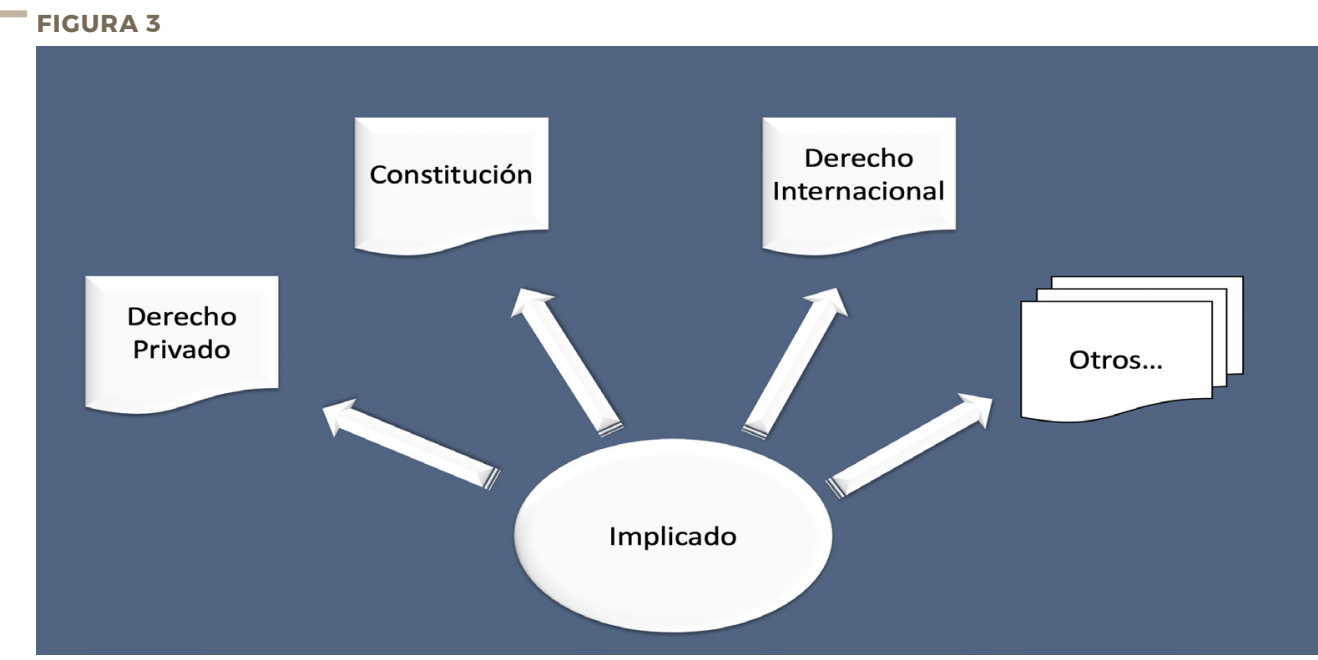

FUENTE: ELABORACIÓN PROPIA.

\subsection{Caso Mapuche}

La identidad mapuche se ha expresado en una constante defensa del espacio geográfico en el que habitaban, demostrando la importancia que este grupo étnico otorga a lo local. Sin embargo, están conectados con distintos grupos indígenas alrededor del mundo y con los organismos internacionales y ONGs que los defienden. Sus reclamos se centran principalmente en la recuperación de sus tierras, el reconocimiento constitucional como pueblo originario y la idea de autogobierno. Como puede observarse, todo vinculado a la identidad apegada al espacio local.

Al revisar el documento "Informe de las víctimas de comunidades y organizaciones Mapuche sobre la Discriminación Racial” al Comité a cargo de estos asuntos en Naciones Unidas ${ }^{2}$, se producen hallazgos interesantes. Una serie de asociaciones mapuches y lonkos, se presentan ante este organismo como "víctimas de actos raciales" que han sido objeto de “exclusión, restricción y omisión de sus derechos, basados en la

2 https://tbinternet.ohchr.org/Treaties/CERD/Shared\%20Documents/CHL/INT_CERD_NGO_CHL_14780_S.pdf 
"Convención Internacional sobre la Eliminación de Todas las Formas de Discriminación Racial", uno de los principales tratados sobre derechos humanos adoptado por las Naciones Unidas. El argumento se sostiene en un recuento de todos los tratados y leyes, nacionales e internacionales, desde la colonia española en adelante, que han sido respetados e irrespetados ${ }^{3}$. Lo interesante de este ejercicio jurídico es que todos los reclamos mencionados podrían hacerse apelando a la constitución chilena mediante un recurso de protección. Sin embargo, se decide apelar al derecho internacional.

Otro ejemplo que cabe destacar es que el dice relación con la recuperación de tierras ancestrales. Si bien el tema se remonta a mediados del s.XIX, se puede decir que entre 1964-1973 la demanda por recuperar las tierras del pueblo mapuche comienza a volverse parte del discurso público, y logra sus primeros éxitos concretos. Sin embargo, durante la dictadura militar se redactan dos leyes que termina quitándole gran parte de las tierras a esta comunidad: La ley 701 sobre fomento forestal - relacionado con la privatización y subdivisión de tierras para la actividad forestal - y luego el Decreto Ley 2.568 sobre división y subdivisión de las tierras indígenas, estableciendo que son tierras indígenas aquellas ya reconocidas por la ley, siempre que no hayan sido divididas, estableciendo que "al momento de aplicarse la división de las tierras dejan de ser indígenas las tierras y sus ocupantes".

En definitiva, según el Alto Comisionado para los Derechos Humanos de Naciones Unidas: "se trataba de un caso de tierras que la reforma agraria había devuelto a los mapuches y que la dictadura privatizó y después vendió a forestales extranjeras" (Comisionado Presidencial para Asuntos Indígenas 2008)

Este es el origen de los actos de violencia que se viven en la zona. Los mapuches reclaman la devolución de sus tierras ancestrales, tierras que la ley chilena establece como

3 Al final del texto se establecen 9 “recomendaciones" las que se resumen de la siguiente manera: 1) Comisión Paritaria entre el Estado Chileno y el Pueblo Mapuche: buscar formulas a la aplicación de los Tratados celebrados entre el Estado Chileno y el Pueblo Mapuche. 2) Que el Estado Chileno reconozca que la Pacificación de la Araucanía constituyó un acto de Lesa Humanidad: pida perdón e inicie un proceso de resarcimiento e indemnización. 3) Se restituya, repare y cuando ello no sea posible una indemnización justa, imparcial y equitativa por las tierras y sus recursos que fueron arrendados por un periodo de 99 años. 4) Cesen de actividades de expansión forestales en el ancestral territorio Mapuche y que se repare e indemnice el daño causado a las comunidades y su cultura. 5) Cese inmediato de la aplicación con personas Mapuche la ley Antiterrorista 18.314. 6) Modificar la ley Araucanía y se proponga el artículo 28 de la Declaración de Naciones Unidas como un instrumento para la búsqueda de solución a las tierras ancestrales Mapuche que hoy son objeto de reivindicación. 7) Que autoridades gubernamentales respeten y reconozcan la promoción y ejercicio del derecho a la libre determinación, basada en el artículo 3 de la Declaración de Naciones Unidas sobre los Derechos de los Pueblos Indígenas y otros instrumentos de derechos humanos. 8) Se oficialice el Idioma Mapuche 9) Que el Estado Chileno adopte sanciones en contra de las autoridades que inciten a la Discriminación Racial y estas sean tipificadas penalmente. 
privadas. 120mil hectáreas de aquellas en disputa son propiedad de la forestal 'Terranova', perteneciente al Holding "Nueva” - de origen Suizo. En un proceso iniciado en 1999 por el líder Mapuche Aucan Huilcamán, la empresa finalmente aceptó devolver a los comuneros de su organización tierras litigiosas en su posesión. El acuerdo se refiere al usufructo de terrenos adyacentes a la forestal, que los mapuches pueden cultivar como si fueran suyos.

Este es otro ejemplo donde un conflicto legal que no se enfrenta apelando a la constitución, existiendo una serie de argumentos de inconstitucionalidad que pudieran levantarse para ello. En cambio, se elige llevar a cabo un acuerdo entre privados.

\subsection{Caso Tribunal Constitucional}

El Tribunal Constitucional es un organismo que también representa la tensión entre lo local y lo global, ya que si bien su función es respetar la constitución y las leyes del estado de Chile, se conecta y se nutre de otros tribunales constitucionales, como por ejemplo, a través de la Conferencia Iberoamericana de Justicia Constitucional, donde, en palabras de un ministro del tribunal: "hablamos de nuestros problemas"4. Estos problemas comunes se relacionan con el impacto de los cambios en la sociedad mundial que afecta de una manera u otra, a todos los tribunales por igual, en tanto deben enfrentarse a nuevas comunicaciones y semánticas que dividen a la sociedad, como el aborto, el reconocimiento de las minorías sexuales, la píldora del día después o la naturaleza del matrimonio como entidad u organización solamente heterosexual. A todos los tribunales han recurrido con acciones o requerimientos en dichas materias y por ende todos han tenido que expedir decisiones.

En el ámbito de los tribunales constitucionales conviven desde hace un tiempo dos criterios respecto de la tensión entre el derecho internacional y la constitución: el ius cogens y el margen de apreciación nacional.

El ius cogens es un término propio del Derecho Internacional, que hace referencia a una cierta conciencia moral de la comunidad internacional, frente a la cual ciertos tratados, aún si no han sido ratificados por un determinado Estado, son perentorios, y superan en jerarquía a las disposiciones legales internas (Ibáñez, 2008; Toloza, 2013).

4 Entrevista a informante clave en el marco del Proyecto Fondecyt 1140106, Demandas por cambios constitucionales en la sociedad mundial. 
Este término incorpora la idea de un "bloque constitucional” proveniente de un ius commune y asociado también al principio pro homine. Específicamente, ius cogens hace referencia a una conciencia moral de la comunidad internacional, frente a la cual ciertos tratados, aún si no han sido ratificados por un Estado, son perentorios, y superan en jerarquía a las disposiciones legales internas. La idea es que existen crímenes de tal grado que vulneran la conciencia colectiva a nivel de humanidad, y por ello es un asunto de humanidad que sean castigados, lo que está consagrado formalmente en el artículo 53 de la Convención de Viena sobre Derechos de los Tratados.

En línea con esto, el principio pro homine dictamina que, presentado frente a una variedad de interpretaciones, el juez siempre debe optar por aquella que favorezca a la persona. Esto, concretamente, implica optar por la interpretación más amplia a la hora de proteger un derecho, y a la más restringida a la hora de limitarlo (Pinto, 1997).

Un ejemplo asociado a este criterio, Marisol Peña, quien fuera presidenta del Tribunal Constitucional hasta agosto de 2014 relata $^{5}$ en 2011 cómo este principio se aplicó en Chile. Se solicitó la inaplicabilidad del artículo 206 del Código Civil que dispone un procedimiento para hacer una demanda por filiación, luego de la muerte de uno de los padres. La ley chilena estipula que esta demanda se podía solicitar en márgenes de tiempo muy limitados y específicos, implicando una alta probabilidad de que la persona se viera legalmente incapacitada de establecer quienes son sus padres.

El juez decidió que era aceptable la petición de inaplicabilidad, apelando a un derecho que no se encuentra reconocido por la Constitución chilena, el derecho a identidad, el que sin embargo sí se encuentra estipulado en diversos tratados internacionales ratificados por Chile y vigentes en el país.

Mediante este ejemplo es posible observar que la ley es la interpretación del juez, lo que se puede entender como clausura operacional, en tanto el operador del derecho produce y reproduce la ley. Sin embargo lo que dictamina el juez como lícito/ilícito no necesariamente hace referencia a la constitución, ya que entiende que tiene la facultad de elegir la fuente desde donde obtiene el criterio para sentenciar.

Visto desde el punto de vista contrario, ante la decisión de un tribunal internacional, un estado puede hacer uso del “margen de apreciación nacional”. Esto corresponde a la facultad discrecional de los Estados para aplicar, en determinados casos, las normas

5 Entrevista a informante clave en el marco del Proyecto Fondecyt 1140106, Demandas por cambios constitucionales en la sociedad mundial. 
propias de ese estado, antes que aquellas estipuladas por tratados internacionales. Esto responde al hecho de que se reconoce la necesidad de control de los asuntos internos que un Estado soberano posee, además del mejor manejo del contexto y la cultura en que acontecen algunos sucesos.

Ante el caso ficticio de que un tribunal internacional establezca como sentencia la devolución de las tierras ancestrales a los mapuches o bien su derecho de autogobierno, el Tribunal Constitucional podría apelar al margen de apreciación nacional, haciendo referencia a la razón de Estado, la soberanía y el principio de autodeterminación de los pueblos. En tal caso, la decisión tomada por un organismo basado en el derecho internacional, podría ser revocada apelando a la constitución.

\section{Conclusión}

Una de las consecuencias de lo observado es que al desligar el tipo de derecho de la estructura organizacional que lo produce, la descripción del derecho como algo nacional o transnacional deja de ser relevante y el actor se encuentra entonces ante la posibilidad de elegir entre grupos de leyes. Entre estos se encuentra la constitución, a la cual se puede o no apelar para enfrentar un conflicto frente a un incumplimiento de expectativas. Se demuestra así la contingencia de la constitución respecto de otras fuentes jurídicas, pues como ley suprema, ya no es necesaria - ni imposible.

Si bien este modelo pareciera simplificar un problema estableciendo que la norma utilizada depende de la decisión del afectado o del juez, es al mismo tiempo una fuente más de complejidad, porque coexisten y se reproducen expectativas normativas distintas, lo que significa un aumento de la indeterminación: ante las diferentes colisiones de expectativas, lo jurídico no necesariamente ofrece una única solución frente al conflicto.

Aldo Mascareño (2012) se ha referido a esto como autocaotización, es decir: la radicalización de la diferenciación interna de los sistemas, con el objeto de procesar complejidad, conduce a la producción de distintas contexturas de diferenciación para un mismo problema. Esta referencia a lo caótico producto de la imposibilidad de detener la evolución de la diferenciación, aumentan los niveles de indeterminación normativa.

Extremando el argumento de la producción y reproducción de normas proveniente de diferentes contextos y con similar importancia para el implicado, podríamos pensar en un momento de la evolución en que las expectativas se especifican y se diver- 
sifican a tal nivel que ya no es claro el establecimiento de las expectativas. Se dispone de tantos cuerpos normativos sobre los cuales legitimar el comportamiento, que es difícil saber qué conducta esperar.

Esto se puede asociar con la idea de inflación que Neves (2013) propone para explicar el elevado uso del concepto de constitución, en esferas que no le son propias. Visto de otro modo, un contexto de inflación normativa, no sólo aumenta la cantidad de normas, sino que éstas además pierden valor: una alta contingencia, es decir, un gran número de posibilidades posibles entre las cuales elegir una norma, puede llevarnos a estar en condiciones de argumentar muchos comportamientos, siendo todos jurídicamente legítimos.

Esta idea también se puede relacionar de alguna manera con la inflación y deflación de símbolos, como componente del sistema funcional, propuestos por Stichweh y la posibilidad de que ello devenga en una crisis del sistema. (Stichweh 2011)

Toda esta reflexión sobre el rol de la constitución en Chile en el contexto de la sociedad mundial nos lleva a comprender la necesidad de redefinirla acorde a un nuevo contexto socio histórico. Si bien es necesario replantear la legitimidad de nuestro orden jurídico, aun cuando es fundamental re concebir una serie de derechos más allá del modelo económico y el derecho de propiedad, es también imprescindible repensar nuestro orden social asumiendo su híper-complejidad y reconociendo el efecto que otros cuerpos normativos tienen, tanto en la generación de expectativas normativas como en sus facultades para resolver cuando éstas han sido defraudadas.

\section{REFERENCIAS}

Ackerman, B. 1999: La política del diálogo liberal. Barcelona. Gedisa.

Comisionado Presidencial para Asuntos Indígenas. 2008: Informe de la Comisión Verdad Histórica y Nuevo Trato con los Pueblos Indígenas.

Góngora, M. 2006: Ensayo Histórico sobre la noción de Etado en Chile en los siglos XiX y XX. Editorial Universitaria. Santiago de Chile.

Hessel, S. 2011: ¡Indígnate! Destino / Planeta: Santiago, Chile.

Ibáñez, D. 2008: La Costumbre Internacional, el Ius Cogens y las obligaciones Erga Omnes. Tesis Universidad de Chile.

Jocelyn-Holt, A. 1992: La Independencia de Chile: Tradición, modernización y mito. Editorial Mapfre. Madrid. 
- CAROLINA BUSCO

Luhmann, N. 1985: A Sociological Theory of Law. Routledge \& Kegan Paul. London.

Luhmann, N. 2002: El derecho de la sociedad. Universidad Iberoamericana / UNAM. México.

Luhmann, N. 2004: Law as social sistema. Oxford University Press. Oxford.

Mascareño, A. 2012: Auto-caotización en la sociedad mundial. Lineamientos para una teoría de la diferenciación contextual. Cinta Moebio 44: 61-105.

Neves, M. 2013: Transconstitucionalism. Hart Publishing. Oxford and Portland.

Pinto, M. 1997: El principio pro homine. Criterios de hermenéutica y pautas para la regulación de los derechos humanos. En M. Abregú, \& C. Courtis, La aplicación de los tratados sobre derechos humanos por los tribunales locales. CELS Editores del Puerto. Buenos Aires.

Stichweh, R. 2011: Towards a general theory of function system crisis. En: The financial crisis in constitutional perspective. The dark side of functional differentiation. 2011, pp. 43-68.

Tironi, E. 1999: La Irrupción de las Masas y el Malestar de las Élites. Ediciones Grijalbo, Santiago, Chile.

Tironi, E. 2002. El cambio está aquí. Editorial Sudamericana. Chile.

Toloza, R. I. 2013: Aplicación judicial en Chile del "ius cogens" como manifestación de la internacionalización del Derecho interno en materia de protección de la dignidad humana. En: Revista de Derecho de la Pontificia Universidad Católica de Valparaíso, 393-417. 